1 Universidade Federal de São Carlos (UFSCar),

Programa de Pós-

Graduação em Gestão da

Clínica - São Carlos (SP)

Brasil.

geovani.gurgel@gmail.com

2 Universidade Federal

de São Paulo (Unifesp),

Programa de Pós-

Graduação em Saúde

Coletiva - São Paulo (SP),

Brasil.

dayanakso@yahoo.com.br

\section{Percepções de usuários e profissionais da saúde da família sobre o Núcleo de Apoio à Saúde da Família}

\author{
Perceptions of users and professionals of the family health about the \\ Family Health Support Center
}

\begin{abstract}
RESUMO O objetivo deste estudo foi explorar a percepção de usuários e profissionais da Estratégia de Saúde da Família sobre o Núcleo de Apoio à Saúde da Família (Nasf). Trata-se de investigação qualitativa, com entrevista semi-estruturada e grupo focal, sob o prisma da análise de conteúdo. Os profissionais demonstraram conhecimento sobre o Nasf, mas dificuldade em conceituar os dispositivos da proposta. Os usuários, embora não reconheçam o núcleo pelo nome, valorizam e descrevem bem o trabalho, na perspectiva de acesso e qualidade do cuidado. As percepções sugerem que a proposta é reconhecida e valorizada pela população e que é necessário fortalecer as práticas de educação permanente e apoio matricial entre os profissionais.
\end{abstract}

PALAVRAS-CHAVE Atenção Primária à Saúde. Saúde da família. Atenção integral à saúde. Serviços de saúde. Políticas públicas de saúde.

ABSTRACT The aim of this study was to explore the perception of users and professionals of the Family Health Strategy about the Family Health Support Center (Nasf). It is a qualitative research, with semi-structured interview and focus group, from the perspective of content analysis. The professionals demonstrated knowledge about the Nasf, but difficulty to conceptualize the devices of the proposal. Users, although do not recognize the nucleus by name, value and describe the work well, in the perspective of access and quality of care. Perceptions suggest that the proposal is recognized and valued by the population and that it is necessary to strengthen the practices of permanent education and matrix support among professionals.

KEYWORDS Primary Health Care. Family health. Comprehensive health care. Health services. Public health policy. 


\section{Introdução}

O Núcleo de Apoio à Saúde da Família (Nasf) foi criado, em 2008, como uma proposta inovadora do Ministério da Saúde para fortalecer e ampliar as ações da Estratégia Saúde da Família (ESF), buscando maior resolutividade a partir da integralidade da atenção (BRASIL, 2008). O Núcleo é constituído por uma equipe multiprofissional com uma proposta de trabalho interdisciplinar em um processo de cogestão do cuidado, com as equipes de ESF, visando superar a lógica fragmentada da saúde. Para isto, faz uso de ferramentas como apoio matricial, clínica ampliada, Projeto Terapêutico Singular (PTS), Projeto de Saúde no Território (PST) e pactuação do apoio (BRASIL, 2010).

O Nasf pode ser constituído por profissionais de diferentes campos do conhecimento, compartilhando as práticas em saúde nos territórios sob responsabilidade das equipes da ESF e/ou das Equipes de Atenção Básica (EqAB) para populações específicas, tais como as ribeirinhas, as fluviais ou as que são atendidas em consultórios na rua (BRASIL, 2008; BRASIL, 2010). Há três modalidades de Nasf - 1, 2 e 3 -, que diferem quanto à carga horária de trabalho e ao número de equipes ESF/EqAB que apoiam (BRASIL, 2012). De acordo com dados do Departamento de Atenção Básica do Ministério da Saúde (DAB/MS), de junho de 2017, foram implantadas 4.342 equipes Nasf no País, sendo 2.490, 853 e 999 das modalidades 1,2 e 3 , respectivamente.

O grupo de profissionais de saúde que participou do estudo de Silva et al. (2012) traz concordância com a Portaria $\mathrm{n}^{\mathrm{o}} 154$ ao destacar a necessidade de o Nasf potencializar a Atenção Primária à Saúde (APS) e ampliar as ações das Equipes de Saúde da Família (EqSF), articulando as redes de atenção à saúde e, assim, otimizando os fluxos de referência e contrarreferência. Trata-se de uma proposta de grande potencial, visando à maior qualidade e resolubilidade na atenção básica. Porém, em se tratando de um projeto novo, ainda em construção, tem apresentado inúmeros desafios, sendo imprescindível pensar e repensar as práticas, a fim de atingir o seu ideal.

Conforme Nascimento e Oliveira (2010), o principal desafio do Nasf é priorizar a qualidade, o que exigirá mudança da cultura organizacional do Sistema Único de Saúde (SUS). Na prática da ESF, observa-se um trabalho limitado a alcançar metas numéricas em cima de atendimentos predeterminados. O Nasf procura superar esta lógica, através da problematização com as equipes e usuários dos serviços acerca do processo saúde/ doença e das possibilidades de enfrentamento das condições de adoecimento, procurando, assim, aumentar a capacidade resolutiva das EqSF (SILVA ET AL., 2012).

Outro desafio é a demanda gerada pela oferta insuficiente da atenção secundária, que pode levar o Nasf a assumir o papel de outros níveis de atenção (LIMA, 2013; SILVA ET AL., 2012). Segundo Oliveira, Rocha e Cutolo (2012), a prática do Nasf é limitada devido à grande demanda reprimida referente a usuários que já estão adoecidos, necessitando de cuidado individualizado. Atualmente, as necessidades de saúde atendidas na ESF, na maioria das vezes, têm exigido soluções rápidas e inadiáveis, enquanto o trabalho do Nasf é baseado em discussão, reflexão e atuação compartilhada, requerendo tempo e disponibilidade. Desta forma, a necessidade de atender a demanda, bem como da resolução rápida de alguns casos, pode gerar discrepância em relação à lógica de trabalho do Nasf (LANCMAN ET AL., 2013).

Para Tesser e Poli Neto (2017), as experiências espalhadas pelo País sugerem que as atuais equipes matriciadoras dos Nasf podem e devem ser progressivamente fundidas com a atenção especializada, absorvendo as atribuições desta última. Equipes análogas aos Nasf, com os demais especialistas médicos, poderiam ser montadas, de modo que todos os especialistas (médicos e de outras profissões) poderiam atuar, na medida do possível 
e com adequações, de forma personalizada e regionalizada, matriciando um conjunto de EqSF, atendendo a população filtrada em corresponsabilização. Tais comunicação, adscrição e longitudinalidade facilitariam a troca de conhecimento entre especialistas e generalistas da APS, com melhora da educação permanente mútua e discussões dos casos limítrofes e duvidosos (também por telefone ou via digital), avançando na superação da tradição viciosa dos ambulatórios especializados isolados e suas mazelas mencionadas, viabilizando a coordenação do cuidado.

Diversos modelos de Nasf foram construídos pelo País, tanto por dificuldades na interpretação acerca do processo de trabalho quanto pelos diferentes modelos de atenção implementados em cada município. Sampaio et al. (2012) relacionam este fato a uma lacuna temporal gerada pela publicação do 'Caderno de Atenção Básica no 27', principal documento ministerial com direcionamentos gerais para a implementação do Nasf, que ocorreu somente um ano após a publicação da Portaria Gabinete do Ministro (GM) $n^{\circ} 154$, de 24 de janeiro de 2008. Além disto, esta mesma Portaria, contemplando a definição das ações e intervenções junto às ESF, assegura que a gestão do processo de trabalho dos Nasf é de responsabilidade de cada município (BRASIL, 2008).

É importante considerar, ainda, que os diferentes modelos de conformação e atuação do Nasf apresentam-se como um aspecto importante a ser considerado para a definição dos resultados possivelmente alcançados. Esta diversidade é decorrente de fatores contextuais referentes à própria complexidade da atenção básica, à falta de compreensão sobre a lógica de atuação do Nasf por equipes e gestores envolvidos, e aos diferentes interesses em jogo relacionados aos distintos modelos de atenção em saúde vigentes.

Essa heterogeneidade do discurso e das práticas do Nasf podem dificultar o trabalho compartilhado entre as equipes, tornando-o fragmentado e desarticulado, contrariando a proposta ideal de clínica ampliada, baseada nos princípios da integralidade e da interdisciplinaridade. A incompreensão acerca da proposta, que pode ser gerada por parte dos profissionais, tanto da ESF quanto do próprio Nasf, pode também causar dúvidas na população com relação a essa nova equipe.

De maneira geral, a proposta de trabalho do núcleo tem provocado resistências em algumas equipes de ESF, que indicam, entre outros elementos, um distanciamento da realidade de trabalho e uma dificuldade no trabalho interdisciplinar exigido pelo apoio matricial, assim como pelo trabalho em saúde como um todo. Além disso, a maneira de organizar o trabalho do núcleo exige das equipes de ESF mudanças na rotina de trabalho, que, em geral, estão concentradas em práticas assistenciais, curativas e individuais. Em meio a estas tensões, somadas às dificuldades advindas das condições de trabalho, os profissionais do Nasf, em diferentes regiões do País, experimentam aquilo que Sousa et al. (2014) denominou como espaço de 'não lugar' nas unidades de saúde.

Considerando o período de implantação dessa proposta, no Brasil, e a complexidade que envolve a prática pautada pelo referencial teórico-metodológico do apoio matricial, um estudo de revisão sistemática identificou uma visão quase utópica do Nasf como potencial indutor de mudanças sobre aspectos complexos do SUS, além de falta de clareza sobre o que se espera alcançar a partir da atuação compartilhada e integrada entre núcleos e equipes apoiadas. Ainda, segundo este mesmo estudo, a literatura analisada traz novos elementos em relação ao que se espera com a implantação do Nasf, destacando a identificação dos objetivos específicos e dos resultados intermediários e finais esperados como um exercício importante para a reflexão e a posterior proposição de indicadores coerentes com as diretrizes da Política Nacional de Atenção Básica, que venham a contribuir para a consolidação e o avanço do Nasf no País (SOUZA; CALVO, 2016). 
Estudos com relação a experiências de apoio matricial são encontrados frequentemente na área de saúde mental, nos quais são apontados aspectos positivos desta prática nas Unidades Básicas de Saúde (UBS) e em equipes de saúde mental, tais como: melhor integração entre equipe; visão de melhora da assistência por parte dos profissionais de saúde; e maior facilidade no atendimento e para encaminhamentos (ONOCKO-CAMPOS ET AL., 2012). Porém, no caso dos Nasf, ainda existe escassez na literatura sobre experiências concretas de ações relacionadas ao apoio matricial.

Por essas razões apontadas, estudar a proposta do Nasf em todas as suas nuances e dimensões se configura como uma necessidade perante a qual este artigo se coloca, construído com base em parte dos resultados da pesquisa de mestrado realizada a partir do Programa de Saúde Coletiva, da Universidade Federal de São Paulo (Unifesp), com o objetivo de analisar a percepção de usuários e profissionais de UBS da família na Zona Leste do município de São Paulo (SP), sobre o processo de trabalho do Nasf.

Acredita-se que a percepção dos profissionais de saúde e usuários pode favorecer o conhecimento de aspectos do trabalho que vem sendo desenvolvido pelo Nasf, bem como apontar possibilidades e contribuir em seu processo dinâmico de construção.

\section{Metodologia}

Tratou-se de um estudo exploratório e descritivo, com abordagem qualitativa, realizado em quatro UBS do bairro de Guaianases, na Zona Leste do município de São Paulo (SP), no período de outubro a dezembro de 2013. Os critérios de inclusão foram: possuir Nasf no serviço e ser unidade sede da equipe Nasf de referência.

Os sujeitos pesquisados foram os profissionais de saúde de nível superior da equipe mínima (médico ou enfermeiro) e usuários cadastrados das UBS selecionadas. A inclusão dos profissionais foi feita devido ao fato de integrarem equipe de referência e trabalharem no Nasf. Foram convidados 24 profissionais, 1 de cada equipe das 4 UBS selecionadas, dos quais 18 aceitaram realizar a entrevista. O ponto de saturação das informações coletadas foi levado em consideração no estudo.

A seleção dos usuários foi realizada de modo intencional, a partir da indicação de cada profissional entrevistado, priorizando o envolvimento do usuário no cotidiano da UBS, ou caso ele fosse líder comunitário e participativo na UBS. Foram indicados 12 usuários, convidados para o grupo focal, em dia e horário marcado, em um local na comunidade, porém apenas 6 compareceram e participaram da pesquisa.

Em função dos números, foram realizadas entrevistas semiestruturadas com os profissionais, e grupo focal com os usuários selecionados, aplicando roteiros diferentes. O roteiro de entrevista foi dividido em duas partes: a primeira, envolvendo dados pessoais do perfil dos profissionais; a segunda, com questões relativas ao processo de trabalho do Nasf. O grupo focal foi norteado por um roteiro de debate também dividido em duas partes: a primeira, referindo-se ao perfil dos usuários; e a segunda, abordando discussão coletiva quanto aos diferentes serviços de saúde, a relação deles com os serviços e o entendimento sobre serviços e profissionais de saúde.

Para o registro das entrevistas e do grupo focal, foi utilizado o aplicativo Easy Voice Recorder $^{\circledR}$, do Tablet Samsumg Galaxy ${ }^{\circledR}$, e observação livre. A identificação dos participantes da pesquisa foi realizada pela seguinte codificação: ' $\mathrm{P}$ ' para os profissionais entrevistados e 'U' para os usuários do grupo focal, que foram numerados de acordo com a ordem de realização da entrevista, para os profissionais, e com a ordem da fala durante o grupo focal, para os usuários. Essa identificação também foi utilizada na apresentação dos resultados e na discussão deste estudo.

Para a apreciação dos dados, utilizou-se 
a análise de conteúdo na modalidade temática que busca compreender o pensamento dos sujeitos por meio das condições empíricas do texto, tendo sido realizada a partir das seguintes etapas: pré-análise; exploração do material; e tratamento e interpretação dos resultados (BARDIN, 2011). Na pré-análise, foi utilizada a técnica da leitura flutuante, com exploração do material transcrito, a fim de conhecer o texto e se deixar invadir por impressões e orientações. A fase seguinte, de exploração do material, consistiu na administração sistemática das impressões tomadas na fase anterior, para a qual se realizou leitura aprofundada de cada entrevista, seguida da produção de análise individual das mesmas, e de uma síntese.

Após a conclusão dessa síntese, com os resultados significativos, foram propostas inferências e realizaram-se interpretações com base nos objetivos traçados, que apontaram os seguintes agrupamentos temáticos como categorias de análise: 1) conhecimento dos participantes acerca da proposta de Nasf; e 2) relação entre as práticas de APS e Nasf. A análise dos discursos dos profissionais e dos usuários foi realizada separadamente, devido à diferenciação das técnicas de coleta de dados, com o intuito de facilitar a compreensão da percepção de cada um dos grupos pesquisados.

A pesquisa foi submetida aos Comitês de Ética e Pesquisa (CEP) da Unifesp e da Secretaria Municipal de Saúde de São Paulo (SMS-SP), e aprovada sob os protocolos $\mathrm{n}^{\circ}$ 326.848 e n ${ }^{\circ} 597.482-0$, respectivamente. Todos os sujeitos participantes da pesquisa assinaram Termo de Consentimento Livre e Esclarecido.

\section{Resultados e discussão}

\section{Percepção dos profissionais de saúde}

A seguir, apresenta-se parte dos resultados e da discussão, a partir das categorias extraídas da leitura e análise das entrevistas com os profissionais de saúde, considerando as percepções destes sobre o processo de trabalho do Nasf.

\section{CONHECIMENTO DOS PROFISSIONAIS DE SAÚDE SOBRE A PROPOSTA DO NASF}

O apoio matricial é o referencial teórico-metodológico que orienta o trabalho do Nasf, e tem como objetivo assegurar retaguarda especializada a equipes e profissionais de saúde, de maneira personalizada e interativa (CUNHA; CAMPOS, 2011). Envolve troca de conhecimentos teórico-práticos, reflexão, discussão e pactuação de responsabilidades para o seguimento das ações (BARROS ET AL., 2015).

Grande parte dos profissionais entrevistados mostrou entendimento acerca da proposta do Nasf, baseando-se na prática do apoio matricial, evidenciando trabalho multiprofissional, troca de saberes, compartilhamento de casos e atendimento conjunto, confirmando o Nasf como uma equipe de apoio matricial à ESF, conforme previsto nas diretrizes. Para os profissionais da ESF, o entendimento que tinham sobre o Nasf estava atrelado fortemente ao apoio matricial:

Apoio para poder tentar ajudar a resolver os problemas que, às vezes, o enfermeiro, o profissional médico, não tem tanto conhecimento. Então, não sabe muito bem como direcionar. (P1).

O Nasf é um grupo multidisciplinar que vem dar um apoio para o pessoal da estratégia. [...] Então, acho que o Nasf vem ajudar nos casos mais complicados, casos mais complexos. (P12).

Contraditoriamente, o estudo de Barros et al. (2015) coloca o apoio matricial como um dos desafios enfrentados pelo Nasf, apontando que este não está totalmente assimilado por todas as equipes de ESF, o que dificulta a efetivação de sua lógica de trabalho. Martinez, Silva e Silva (2015) relatam que a maioria das ferramentas tecnológicas do processo de trabalho do Nasf (clínica ampliada, PTS e PST) 
ainda são pouco conhecidas pela maioria dos profissionais da ESF, bem como, por alguns dos integrantes do Nasf.

Na prática do Nasf, deve ocorrer a compreensão do que é conhecimento nuclear do especialista e do que é conhecimento comum e compartilhável entre a equipe da ESF (equipe de referência) e o referido especialista. A equipe de referência é considerada essencial na condução de problemas de saúde dos usuários do serviço e deverá acionar o apoio quando perceber dificuldades em lidar com alguns casos (BRASIL, 2010). Segundo Matuda (2012), o profissional da ESF considera a importância da equipe de apoio através da ampliação das possibilidades de atuação e pelo conhecimento adquirido na interação com o outro, quando reconhece e incorpora seu papel na responsabilização dos casos. Neste sentido, alguns profissionais mostraram conhecimento sobre o conceito do apoio matricial, trazendo uma definição mais ampla, a partir da aquisição de novos conhecimentos, contribuindo para outras opções de atuação na prática:

Apoio matricial, eu entendo que são situações, assim, específicas, na qual eu não tenho domínio. Então, são profissionais que tem conhecimento que eu não tenho e que vêm colaborar o meu trabalho, enriquecendo meu conhecimento e dando ferramentas, né? Trazendo ferramentas para que eu possa trabalhar. (P4).

Apoio matricial é quando o profissional vem na unidade, quando um especialista da área vem ajudar a gente a entender alguns processos e deixar a gente capacitado para estar atendendo alguns problemas [...] que a gente antes não tinha condições de estar avaliando. (P12).

O apoio matricial sugere uma lógica de corresponsabilização territorial que vem, ao contrário do método tradicional de encaminhamentos indiscriminados, buscando maior resolutividade (NASCIMENTO; OLIVEIRA, 2010). Para Andrade et al. (2012), as ações de apoio devem diminuir os encaminhamentos e não contribuir para o aumento da referência ou de encaminhamentos novos a outros serviços. No estudo de Silva et al. (2012), profissionais de saúde (ESF e Nasf) relatam que o Nasf precisa potencializar a APS, ampliando as ações das equipes, além de articular com as redes de saúde, otimizando os fluxos de referência e contrarreferência. Ajudar as equipes a evitar ou qualificar os encaminhamentos faz parte das competências do Nasf (BRASIL, 2014). As falas a seguir evidenciam a prática de apoio matricial ainda na lógica do fortalecimento dos encaminhamentos, sugerindo que o Nasf deve funcionar para referenciar os casos discutidos, e reforçando que a prática realizada, apesar de condizente com a proposta da ferramenta, ainda se volta predominantemente para solucionar o gargalo do atendimento secundário.

Apoio matricial é me orientar como ter acesso a todas as redes e saber direcionar o que é de quem. (P13).

Então, a gente faz esse matriciamento diretamente com eles, pra poder referenciar, se possível. (P15).

Outra ferramenta de trabalho proposta para o Nasf é a clínica ampliada, que deve funcionar como norteadora do intuito de atuar de forma integral e desfragmentada, visando melhorar a qualidade do serviço ofertado (NASCIMENTO; OLIVEIRA, 2010). Lima (2013) confirma que as ações do Nasf, bem como da ESF, devem visar à qualidade e à resolubilidade, aspectos esses que regem a clínica ampliada. Além disto, Matumoto (2011) indica que os enfermeiros conseguem enxergar o fazer clínico de formas diferentes a partir do entendimento da clínica centrada no usuário, contemplando a prática da ferramenta.

Apesar de fazer parte da Política Nacional de Humanização (PNH), a clínica ampliada parece não ser conhecida pelos profissionais entrevistados, pelo menos, enquanto definição. Foi percebida confusão no entendimento do conceito, tornando-a restrita ao acesso 
à unidade de saúde, e alguns profissionais relataram desconhecê-la, conforme se exemplifica nas falas a seguir:

A clínica ampliada seria o acesso que damos aos usuários, uma vez por mês, com consultas médicas, tanto de clínica como de ginecologia, de pediatria, integrais, para orientar. (P7).

Agora, clínica ampliada, nunca ouvi falar. (P1).

Portanto, para o desenvolvimento do trabalho na ESF, além do conhecimento técnico, são esperados outros conhecimentos, tais como: políticas públicas de saúde, território, perfil epidemiológico da população, rede de cuidados e habilidade para abordar o paciente, acolher, ouvir e comunicar-se com ele (NASCIMENTO; OLIVEIRA, 2010). O estudo de Silva et al. (2012) sugere que é preciso reconsiderar a agenda e a organização do trabalho do Nasf, quanto aos atendimentos individuais e à construção do trabalho interdisciplinar, para uma maior qualidade do cuidado.

Os aspectos referenciados acima visam a uma abordagem ampliada, que se faz necessária para efetivar o cuidado integral em saúde e é esperado para o trabalho do Nasf. Os entrevistados apresentam a percepção de que os profissionais de Nasf possuem uma abordagem mais ampliada, voltada às ações de promoção e prevenção, para intervirem em casos mais complexos, de maior vulnerabilidade, e no enfoque familiar:

Nasf é nosso apoio em relação às ações, à comunidade, porque a maior parte da demanda [...] são problemas sociais, e eles têm uma experiência mais ampla [...]. O Nasf tem um entendimento maior da família... (P11).

\section{RELAC̣ÃO ENTRE AS PRÁTICAS DA ESF E DO NASF}

$\mathrm{O}$ apoio do Nasf às equipes deve se basear na produção de um cuidado continuado e longitudinal, próximo da população e na perspectiva da integralidade, conforme as diretrizes da atenção básica (BRASIL, 2012).

Assim, cabe ao Nasf contribuir na discussão junto aos gestores sobre os indicadores de saúde relacionados com a qualidade do cuidado prestado à população, com o intuito de refletir sobre a ineficácia da valorização de metas simplesmente quantitativas, pois estas não medem o impacto das ações nem são suficientes para avaliar a qualidade do cuidado (SILVA ET AL., 2012).

Quando questionados sobre as atividades desenvolvidas no serviço, e que são comuns entre Nasf e ESF, os profissionais relacionaram, em sua grande maioria, as atividades em grupo: "Os grupos de orientações mesmo. [...] São esses grupos, que mais parece" (P9). "Acho que a parte mesmo de grupos, de orientações...” (P10).

Na prática, as equipes do Nasf são responsáveis por vários grupos (terapêuticos, temáticos, educativos, oficinas etc.), com ou sem a parceria das equipes da ESF. Devido aos diferentes modelos de gestão e da prática de trabalho entre Nasf e ESF, além das grandes demandas e metas de produtividade da ESF, os grupos acabam sendo centralizados nos profissionais de Nasf (GONÇALVES, 2015).

Os profissionais do Nasf devem propor ações que busquem ir além dos grupos prioritários, visando ampliar as intervenções da ESF, que ainda enfoca um modelo centrado na doença (OLIVEIRA; ROCHA; CUTOLO, 2012).

Nessa perspectiva, se encontram as atividades isoladas da $\mathrm{ESF}$, que não condizem com a prática de trabalho do Nasf, relatadas pelos profissionais entrevistados, e que são relacionadas com a atuação específica médica ou de enfermagem, tais como: intervenções com medicação, exames, supervisão e urgências. Ou seja, há um predomínio de práticas mais curativas.

A terapêutica de doenças mesmo [...] e farmacológica, que o Nasf não faz. (P11). 
Acho que, basicamente, é questão de troca de receitas [...] e isso aí, o Nasf não precisa fazer. (P12).

Esse resultado espelha o encontrado em um estudo realizado em Fortaleza (CE), no qual os profissionais do Nasf apontaram que as ações da ESF eram voltadas, predominantemente, para a assistência baseada em protocolos consolidados (OLIVEIRA; ROCHA; CUTOLO, 2012).

Conforme Lima (2013), as ações realizadas entre os profissionais de Nasf se assemelham com as atividades desenvolvidas entre Nasf e ESF, e devem visar à clínica ampliada, a partir do atendimento compartilhado e da intervenção interdisciplinar, com troca de saberes, capacitação e responsabilidades mútuas, gerando conhecimento para todos os profissionais envolvidos. Considerando que a ESF encontra-se em um panorama fortemente influenciado pelo modelo biomédico e se propõe a romper com tal modelo assistencial, este segue sendo um grande desafio para a construção da nova prática (VIEGAS; PENNA, 2013).

\section{Percepção dos usuários}

Os resultados e a discussão apresentados abaixo emergem a partir do estudo com o grupo dos usuários, que se centrou em torno da percepção dos mesmos acerca de sua relação com o Nasf.

O estudo de Souza et al. (2013B) evidenciou que os usuários não reconhecem a equipe Nasf pela sigla. No entanto, existem pesquisas nas quais os usuários atribuem as ações do Nasf à melhoria da qualidade de vida, mas, nesses casos, a coleta de dados foi realizada imediatamente após os sujeitos participarem das atividades do Nasf (NÓBREGA, 2013; SOUZA ET AL., 2013B), possivelmente, facilitando o reconhecimento da equipe.

Quando da realização do grupo focal, sobre o que entendiam das atividades do Nasf, observou-se que os usuários participantes relataram total desconhecimento em relação à sigla ou ao seu significado. "Eu ouvi falar, mas não me profundei ainda" (U1). "Eu não sei, nunca ouvi falar" (U4). "Não sei mesmo o que é" (U3).

Para Souza et al. (2013B), existe o reconhecimento das atividades realizadas pelo Nasf, mesmo quando estas não são associadas ao nome da proposta. Legitimando as considerações do autor acima, as falas a seguir demonstram o reconhecimento das categorias profissionais do Nasf, tais como nutricionistas, fisioterapeutas, terapeutas ocupacionais e fonoaudiólogos, de forma atuante na UBS, pois os usuários frequentam atividades desenvolvidas por estes profissionais.

[...] Falei da nutricionista porque eu perguntei pra ACS [Agente Comunitária de Saúde] [...] e ela falou para ele participar de um grupo que tem aqui, de segunda-feira [...]. (U4).

[...] por exemplo, crianças que têm problema de fonoaudióloga, têm grupos que atende [...]. (U2).

A participação nas atividades do Nasf também não é impedida pela falta de compreensão da definição ou sigla, porém pode comprometer a articulação entre as ações realizadas e uma proposta de saúde, no futuro (SOUZA ET AL., 2013A). O discurso abaixo relata a participação do usuário em duas atividades distintas do Nasf, porém, para ele, parece não importar quem são e/ou de onde são esses profissionais de saúde. Esta 'não identificação' do Nasf pode ser esperada, se for pensada sob a perspectiva da transdisciplinaridade.

[...] Na segunda-feira, às 10 horas da manhãa, eles fazem as coisas pros idosos, lá. É terapia ocupacional. [...] pra quem também tem problema de tendinite, artrite, artrose, essas coisas. Eu participava também na fisioterapia. (U3).

$\begin{array}{ccc}\text { Tentando definir o trabalho do } & \text { dón } \\ \text { Nasf, dois usuários arriscaram e }\end{array}$ 
acabaram confundindo-o com alguns serviços de atenção domiciliar que são ofertados na região pesquisada pelo SUS, ou por convênios privados de saúde.

O Nasf é aquele [...] que eles levam as aparelhagens para fazer o tratamento em casa [...] ao invés de ficar no hospital, eles ficam em sua própria residência [...]. (U1).

Seria mais um home care? [...] quando as pessoas precisam de fralda, colchão ou alguma coisa especializada? (U3).

Os dados revelam a percepção dos usuários frente à importância da ação multidisciplinar na qual estão envolvidos, porém também afirmam que falta divulgação de tais atividades (SOUZA ET AL., 2013B). Para Souza et al. (2013A), fica clara a necessidade de divulgação, para a comunidade, do atendimento multiprofissional, cuja cobertura ainda é pequena.

\section{Conclusões}

Uma vez que a saúde da família representa uma estratégia prioritária para a reformulação do modelo assistencial, com o intuito de fortalecer a atenção primária, no País, e garantir a universalidade e a integralidade no cuidado à saúde, a incorporação de outros profissionais, através do Nasf, fez-se necessária para expandir as ações em saúde na ESF e contribuir para uma maior resolutividade na APS.

Em relação à percepção dos profissionais da ESF sobre o Nasf, o entendimento da lógica de trabalho a partir do apoio matricial, do compartilhamento de saberes e das práticas, ainda que polimorfo e pouco aprofundado, já representa um aspecto positivo, pois supõe que o Nasf conseguiu transmitir essa visão às equipes de ESF. Por outro lado, sobre as atividades desenvolvidas pelo Nasf na UBS, não houve a menção de ações relacionadas ao matriciamento, ou de apoio matricial, o que sugere que, apesar do entendimento sobre a ferramenta, sua prática ainda não está consolidada enquanto rotina.

A presente investigação também mostrou imitações acerca do conhecimento mais aprofundado sobre a clínica ampliada, observando pouco ou nenhum embasamento, por parte dos profissionais da ESF. Estes aspectos relacionados ao entendimento de conceitos e práticas de trabalho sugerem um investimento em educação permanente, com as equipes no cotidiano do trabalho, que pode ser realizado pela própria equipe Nasf.

Em relação aos usuários, o Nasf não foi reconhecido pela sigla, mas houve relatos sobre participações em atividades realizadas na UBS por profissionais do Nasf. Esta 'não identificação' nominalista, por parte dos usuários, pode ser esperada caso seja pensada sob a perspectiva da transdisciplinaridade. E permite especular que, para a população, o mais importante talvez seja como os serviços de saúde se apresentam em termos de acesso e qualidade do cuidado, especialmente na perspectiva multiprofissional, sendo menos importante o nome que esses serviços recebem dos arranjos gerenciais ou programas governamentais criados para induzir e estruturar políticas públicas.

A comparação da percepção dos profissionais com a dos usuários, sobre o Nasf, sugere que a proposta idealizada é reconhecida e valorizada pela população, talvez mais até do que pelas próprias equipes de saúde. Um serviço multidisciplinar voltado à atenção básica tem impacto na percepção dos indivíduos por ser uma lógica diferenciada. Entretanto, as ações necessitam ser constantemente fortalecidas (SOUZA ET AL., 2013A). Neste sentido, parece recomendável um investimento maior no fortalecimento da proposta de trabalho do Nasf, com as equipes de saúde, especialmente enfocando os aspectos conceituais e operativos da educação permanente e do apoio matricial, reforçando os dispositivos da clínica ampliada e estimulando os arranjos organizacionais que expandam 
os espaços coletivos de gestão e discussão do trabalho entre as equipes.

Apesar de poder ser considerada em construção, a proposta do Nasf já completa dez anos, e já revela um arco amplo que engloba distintas ações, formatos e interpretações. Diante da amplitude do tema, outras percepções e aspectos relacionados ao Nasf podem agregar reflexões, na expectativa de fortalecimento da proposta, a fim de sempre melhorar a resolutividade e efetivar a integralidade na APS.

\section{Colaboradores}

Os autores trabalharam igualmente em todas as etapas de elaboração do artigo.

\section{Referências}

ANDRADE, L. M. B. et al. Análise da implantação dos núcleos de apoio à saúde da família no interior de Santa Catarina. Saúde e Transformação Social, Florianópolis, v. 3, n. 1, p. 18-31, 2012. Disponível em: <http://pepsic.bvsalud.org/scielo.php?pid=S2178$-70852012000100005 \&$ script=sci_arttext $>$. Acesso em: 5 jun. 2015 .

BARDIN, L. Análise de conteúdo. São Paulo: Edições 70, 2011.

BARROS, J. O. et al. Estratégia do apoio matricial: a experiência de duas equipes do Núcleo de Apoio à Saúde da Família (NASF) da cidade de São Paulo, Brasil. Ciência \&t Saúde Coletiva, Rio de Janeiro, v. 20, n. 9, p. 2847-2856, 2015. Disponível em: <http://www. redalyc.org/articulo.oa?id=63041075025 $>$. Acesso em: 9 ago. 2017.

BRASIL. Ministério da Saúde. Portaria GM n ${ }^{\circ}$ 154, de 24 de janeiro de 2008. Dispõe sobre a criação dos Núcleos de Apoio à Saúde da Família. Diário Oficial [da] República Federativa do Brasil, Brasília, DF, 2008. Disponível em: <http://189.28.128.100/dab/docs/legislacao/portaria154_24_01_08.pdf >. Acesso em: 13 out. 2014.

. Ministério da Saúde. Portaria GM no 3.124, de 28 de dezembro de 2012. Núcleos de Apoio à Saúde da Família. 2012. Disponível em: <http://bvsms.saude. gov.br/bvs/saudelegis/gm/2012/prt3124_28_12_2012. html>. Acesso em: 14 fev. 2013.

Ministério da Saúde. Departamento de Atenção Básica. Diretrizes do Nasf: Núcleo de Apoio à Saúde da Família. Brasília, DF: Ministério da Saúde, 2010. Disponível em: <http://bvsms.saude.gov.br/bvs/publicacoes/caderno_atencao_basica_diretrizes_nasf.pdf>. Acesso em: 20 nov. 2014.

Ministério da Saúde. Departamento de Atenção Básica. Núcleo de Apoio à Saúde da Família: ferramentas para a gestão e para o trabalho cotidiano. Brasília, DF: Ministério da Saúde, 2014. Disponível em: <http:// 
bvsms.saude.gov.br/bvs/publicacoes/nucleo_apoio_ saude_familia_cab39.pdf>. Acesso em: 3 jan. 2014.

CUNHA, G. T.; CAMPOS, G. W. S. Apoio matricial e atenção primária em saúde. Saúde e Sociedade, São Paulo, v. 20, n. 4, dez. 2011. Disponível em: $<$ http://www.scielo.br/scielo.php?script=sci arttext\&pid=S0104-12902011000400013\&lng=en\&nrm =iso>. Acesso em: 3 jan. 2014.

GONÇALVES, R. M. A. et al. Estudo do trabalho em Núcleos de Apoio à Saúde da Família (NASF), São Paulo, Brasil. Revista Brasileira de Saúde Ocupacional, São Paulo, v. 40, n. 131, p. 59-74, 2015. Disponível em: <http://www.scielo.br/scielo.php?script=sci arttext\&pid=S0303-76572015000100059\&lng=en\&nrm =iso\&tlng=pt $>$. Acesso em: 9 ago. 2017.

LANCMAN, S. et al. Estudo do trabalho e do trabalhar no Núcleo de Apoio à Saúde da Família. Revista de Saúde Pública, São Paulo, v. 47, n. 5, out., 2013. Disponível em: <http://www.scielosp.org/scielo. php?pid=S0034-89102013000700968\&script=sci_arttext>. Acesso em: 9 abr. 2014.

LIMA, F. L. C. O núcleo de apoio à saúde da família e alguns dos seus desafios. Revista Saúde e Desenvolvimento, Brasília, DF, v. 3, n. 2, jan./jun. 2013. Disponível em: <http://www.grupouninter.com.br/revistasaude/index.php/saudeDesenvolvimento/article/ view/144/114>. Acesso em: 3 jan. 2014.

MARTINEZ, J. F. N.; SILVA, M. S. S.; SILVA, A. M. O Núcleo de Apoio à Saúde da Família em Goiânia (GO): percepções dos profissionais e gestores. Saúde em Debate, Rio de Janeiro, v. 40, n. 110, p. 95-106, jul./ set. 2016. Disponível em: <http://www.redalyc.org/ html/4063/406347806008/>. Acesso em: 3 jan. 2014.

MATUDA, C. G. Cooperação interprofissional: percepções de profissionais da estratégia saúde da família no município de São Paulo (SP). 2012. 155 f. Dissertação (Mestrado em Saúde Pública) - Faculdade de Saúde Pública, Universidade de São Paulo, São Paulo, 2012. Disponível em: <http://www.teses.usp.br/teses/disponiveis/6/6135/tde-26102012-102123/pt-br.php >. Acesso em: 19 maio 2014 .
MATUMOTO, S. et al. A prática clínica do enfermeiro na atenção básica: um processo em construção. Revista Latino-Americana de Enfermagem, Ribeirão Preto, v. 19, n. 1, jan./fev. 2011. Disponível em: <http://www.scielo.br/scielo.php?pid=S0104$-11692011000100017 \&$ script $=$ sci_arttext\&tlng=pt $>$. Acesso em: 5 abr. 2015.

NASCIMENTO, D. D. G.; OLIVEIRA, M. A. C. Reflexões sobre as competências profissionais para o processo de trabalho nos Núcleos de Apoio à Saúde da Família. O Mundo da Saúde, São Paulo, v. 34, n. 1, p. 92-96, 2010. Disponível em: <http://www.saocamilo-sp. $\mathrm{br} / \mathrm{pdf} /$ mundo_saude/74/12_revisao_reflexoes.pdf $>$. Acesso em: 30 fev. 2014.

NÓBREGA, J. S. M. Avaliação das ações do núcleo de apoio à saúde da família (NASF) em Macaíba/RN. 2013. 68 f. Dissertação (Mestrado em Saúde Pública) Universidade Federal do Rio Grande do Norte, Natal, 2013. Disponível em: <http://bases.bireme.br/cgi-bin/ wxislind.exe/iah/online/>. Acesso em: 29 maio 2014.

OLIVEIRA, I. C.; ROCHA, R. M.; CUTOLO, L. R. A. Algumas palavras sobre o Nasf: relatando uma experiência acadêmica. Revista Brasileira de Educação Médica, Rio de Janeiro, v. 36, n. 4, dez. 2012. Disponível em: <http://www.scielo.br/scielo.php?pid=S0100$-55022012000600019 \&$ script $=$ sci_abstract\&tlng $=$ pt $>$. Acesso em: 20 maio 2014.

ONOCKO-CAMPOS, R. et al. Avaliação de estratégias inovadoras na organização da Atenção Primária à Saúde. Revista de Saúde Pública, São Paulo, v. 46, n. 1, 2012. Disponivel em: <http://www.scielo.br/scielo. php?pid=S0034-89102012000100006\&script=sci_arttext>. Acesso em: 5 abr. 2015.

SAMPAIO, J. et al. O Nasf como dispositivo da gestão: limites e possibilidades. Revista Brasileira de Ciências da Saúde, João Pessoa, v. 16, n. 3, p. 317-324, 2012. Disponível em: <http://periodicos.ufpb.br/ojs/index. $\mathrm{php} / \mathrm{rbcs} /$ article/view/12572/7870 >. Acesso em: 20 maio 2015

SILVA, A. T. C. et al. Núcleos de apoio à saúde da família: desafios e potencialidades na visão dos profissionais 
da Atenção Primária do Município de São Paulo, Brasil. Cadernos de Saúde Pública, Rio de Janeiro, v. 28, n. 11, nov. 2012. Disponível em: <http://www.scielo.br/scielo. php?script=sci_arttext\&pid=S0102-311X201200110000 $7 \& \operatorname{lng}=\mathrm{en} \& \mathrm{nrm}=\mathrm{iso}>$. Acesso em: $8 \mathrm{dez} .2014$.

SOUSA, F. O. S. et al. Do normativo à realidade do sistema único de saúde: revelando barreiras de acesso na rede de cuidados assistenciais. Ciência \& Saúde Coletiva, Rio de Janeiro, v. 19, n. 4, p. 1283-1293, 2014. Disponível em: <http://www.scielo.br/scielo. php?pid=S1413-81232014000401283\&script $=$ sci abstract\&tlng=pt>. Acesso em: 1 dez. 2017.

SOUZA, T. T.; CALVO, M. C. M. Resultados esperados dos Núcleos de Apoio à Saúde da Família: revisão de literatura. Saúde e Sociedade, São Paulo, v. 25, n. 4, p. 976987, 2016. Disponível em: <http://www.scielo.br/scielo. php?pid=S0104-12902016000400976\&script $=$ sci abstract\&tlng=pt $>$. Acesso em: 29 maio 2015.

SOUZA, F. L. D. et al. Implantação do núcleo de apoio a saúde da família: percepção do usuário. Saúde em Debate, Rio de Janeiro, v. 37, n. 97, p. 233-240, abr./jun. 2013a. Disponível em: <http://www.scielo.br/pdf/sdeb/ v37n97/v37n97a05.pdf>. Acesso em: 19 maio 2015.
SOUZA, F. L. D. et al. Percepções sobre qualidade de vida das usuárias de um núcleo de apoio à saúde da família. Investigação, Franca, v. 13, n. 3, p. 34-38, 2013 b. Disponível em: <http://publicacoes.unifran.br/index. php/investigacao/ article/view/791/614>. Acesso em: 29 maio 2015.

TESSER, C. D.; POLI NETO, P. Atenção especializada ambulatorial no Sistema Único de Saúde: para superar um vazio. Ciência \&t Saúde Coletiva, Rio de Janeiro, v. 22, n. 3, p. 941-951, mar. 2017. Disponível em: <http://www.scielo.br/scielo.php?pid=S1413$-81232017002300941 \&$ script=sci_abstract\&tlng=pt $>$. Acesso em: 29 maio 2015.

VIEGAS, S. M. F.; PENNA, C. M. M. A construção da integralidade no trabalho cotidiano da equipe saúde da família. Escola Anna Nery, Rio de Janeiro, v. 17, n. 1, mar. 2013. Disponível em: <http:// www.scielo.br/scielo.php?script=sci_arttext\&pid $=$ S1414-81452013000100019>. Acesso em: 3 dez. 2013.

Recebido para publicação em maio de 2017

Versão final em agosto de 2017

Conflito de interesses: inexistente

Suporte financeiro: não houve 